\title{
Astronomy: Social representations of students of integrated high school
}

\author{
Marcos Rincon Voelzke ${ }^{1,2}$, José Isnaldo de Lima Barbosa ${ }^{1,3}$ \\ ${ }^{1}$ Universidade Cruzeiro do Sul - Brazil 01506-000; ${ }^{2}$ Institut für Geophysik und extraterrestrische \\ Physik -Technische Universität Braunschweig - Germany; ${ }^{3}$ Instituto Federal de Alagoas - Brazil \\ 57120-000.
}

\begin{abstract}
The contents related to Astronomy studied in basic education in Brazil are not always adequately worked, as their exposure in the media is often full of sensationalism, however, it is in this environment that students form their opinions about this science. Therefore, in this work we present the possible Social Representations that students of the Integrated High School of the Federal Institute of Alagoas (IFAL) have with the term inductor Astronomy. Additionally, we identify how these Social Representations were elaborated. There is a basic and descriptive research, and the procedures for obtaining the data occurred in the form of a survey, the subjects involved were 653 students from the Integrated High School. The results indicate that the surveyed students have social representations of the object Astronomy, which are based on elements from the formal education space, and also disclosed in the media, in addition, demonstrate that the students have information about Astronomy, and a value position in relation to this science.
\end{abstract}

\section{Introduction}

The official documents that guide the construction of the curricular components of basic education in Brazil, determine that Astronomy topics should be studied from the earliest years of elementary education, since "the role of Astronomy includes promoting public interest, appreciation and approximation by general science". In addition, "as content to be taught, Astronomy also has some degree of motivating potential for both students and teachers", they are characterized by having "an inherently interdisciplinary universality and character" [1] and is therefore fundamental in the process of forming a scientific culture among citizens.

On the other hand, in the present day, the students investigated here have a strong connection with the media, that is, "most individuals in society do not recognize themselves in a life in modern society without coexistence with media products, regardless of predilection of vehicles" [2]. In this context, topics related to Astronomy have a significant space of exposure through the mass media.

Thus, transiting between these two means, that is, the formal education system and the mass media students are forming their opinions about the phenomena studied by Astronomy, so these interactions can forge a way for the term inductor Astronomy can be 
an object capable of being a carrier of social representations among the social group surveyed.

In this sense, the Theory of Social Representations (TSR), is appropriate to this study, because, in consonance with [3] and [4], social representations represent those phenomena that arise through the dialogue between individual and society, are dynamic and specific structures of the current collectivity, which have in the mass media their greatest multiplier. Thus, for [3] social representation "is a form of knowledge, socially elaborated and shared, with a practical objective, and that contributes to the construction of a reality common to a social set".

In order to identify the possible social representations of the investigated students in relation to the term inductor Astronomy, the Central Nucleus Theory (CNT) was used, which is complementary to TSR, and was initially proposed through a hypothesis on the internal composition of social representations, elaborated in "the organization of a social representation presents a specific characteristic, that of being organized around a central nucleus, constituting itself in one or more elements, which give meaning to the representation" [5].

According to the CNT, in addition to the central system, a social representation is also constituted of other elements called peripheral, for [6] these can be considered "as schemas organized around the central nucleus, which in turn is responsible for structuring and stability, generating the meaning that goes through the entire representation".

\section{Methodology}

In order to identify the Social Representations of Astronomy by students of Integrated High School, the Central Nucleus Theory was adopted, conform this theory, the instrument of data collection was a questionnaire called free association and hierarchical. This instrument was applied to 653 students from IFAL, 267 from the 1st year, 219 from the 2nd year and 167 from the 3rd year. The predominant age groups are: 1st year (14 to 17 years); 2 nd year (15 to 18 years); 3 rd year (16 to 19 years). The questionnaire was structured with the following questions:

1 - When thinking about the term "ASTRONOMY", write all the words you have remembered and try to register as many of them in the following table (32 spaces) in order to complete it. Attention, DO NOT fix your attention on the last word you wrote, but on the term "ASTRONOMY".

2 - Among those words recorded in question 1, select and rewrite in the first column of the following table the eight words that you consider most important, that is, most related to the term "Astronomy". Next to the second column, classify each one by its degree of importance from 1 to 8 , with grade 1 being the most important, grade 2 being the 2 nd most important, and so on until grade 8 , which will be the least important.

From the data obtained with the proposed questionnaire, a prototypical analysis was performed according to the CNT, which is also called an evocation analysis or a four-frame study that "is one of the most widespread techniques for structural characterization of a social representation" [7]. This technique is based on the calculation of frequency and order of evocation of words, and therefore applies to data obtained through free association of words, stimulated by a term inducer.

The procedures for obtaining the four-house chart are summarized in the example shown in Table 1 below, in this case two evoked words are considered, in columns 2 to 9 , the quantities that each of these words were quoted are placed in each one of the 8 positions highlighted in question 2 of the questionnaire. Thus, for each of these words its frequency (F) and its mean recall order (MRO) are calculated. Thus, the frequency (F) represents the number of times a given word was mentioned, and the mean order of recall (MRO) 
indicates the position in which the term evoked was hierarchized by the respondent, so this coordinate expresses the degree of importance given to each word, the smaller its value, the more significant will be the word quoted in relation to the term inductor. The MRO is calculated by a weighted average, considering the word 2 , we have:

$$
\mathrm{MRO}=(77 * 1+36 * 2+24 * 3+29 * 4+16 * 5+10 * 6+15 * 7+14 * 8) / 221=3,14
$$

Table 1: Example, frequency calculation and MRO.

\begin{tabular}{|c|c|c|c|c|c|c|c|c|c|c|}
\hline & $\begin{array}{c}\text { Hierarchy } \\
1\end{array}$ & $\begin{array}{c}\text { Hierarchy } \\
2\end{array}$ & $\begin{array}{c}\text { Hierarchy } \\
3\end{array}$ & $\begin{array}{c}\text { Hierarchy } \\
4\end{array}$ & $\begin{array}{c}\text { Hierarchy } \\
5\end{array}$ & $\begin{array}{c}\text { Hierarchy } \\
6\end{array}$ & $\begin{array}{c}\text { Hierarchy } \\
7\end{array}$ & $\begin{array}{c}\text { Hierarchy } \\
8\end{array}$ & & \\
\hline Words & $\begin{array}{c}\text { Number } \\
\text { Evocations }\end{array}$ & $\begin{array}{c}\text { Number } \\
\text { Evocations }\end{array}$ & $\begin{array}{c}\text { Number } \\
\text { Evocations }\end{array}$ & \begin{tabular}{|c|} 
Number \\
Evocations
\end{tabular} & \begin{tabular}{c|c|} 
Number \\
Evocations
\end{tabular} & $\begin{array}{c}\text { Number } \\
\text { Evocations }\end{array}$ & $\begin{array}{c}\text { Number } \\
\text { Evocations }\end{array}$ & $\begin{array}{c}\text { Number } \\
\text { Evocations }\end{array}$ & $F$ & $M R O$ \\
\hline $\begin{array}{c}\text { Word } \\
1\end{array}$ & 15 & 15 & 15 & 12 & 9 & 10 & 14 & 19 & 109 & 4,52 \\
\hline $\begin{array}{c}\text { Word } \\
2\end{array}$ & 77 & 36 & 24 & 29 & 16 & 10 & 15 & 14 & 221 & 3,14 \\
\hline
\end{tabular}

Finally, it is necessary to calculate the average of the frequencies assigned to each word $\left(\mathrm{F}_{\text {average }}\right)$, as well as the average of the average order of evocations $\left(\mathrm{MRO}_{\text {average}}\right)$, these processes, done by arithmetic mean.

For this investigation, the mentioned calculations were performed by the IRAMUTEQ [7] software automatically, thus obtaining the mentioned quantities, that is, the average frequency $\left(\mathrm{F}_{\text {average }}\right)$, and the average of the average order of evocation $\left(\mathrm{MRO}_{\text {average }}\right)$, thus "coordinates, classified in high and low values, generates four zones that characterize the results table of the prototypical analysis" [8], which has a structure shown in Table 2 below, where in the first quadrant are the constituent elements of the central nucleus, and in the other 3 quadrants are the peripheral system elements. It is worth clarifying that in the contrast zone are the elements that denote the representation of subgroups.

Table 2: Structure of the four-house chart, resulting from the prototypical analysis.

\begin{tabular}{|c|c|}
\hline First quadrant & Second quadrant \\
\hline Central Core & First Periphery \\
\hline $\begin{array}{c}\text { Frequency }(F) \geq \text { Frequency Average and } \\
M R O<M R O \text { Average }\end{array}$ & $\begin{array}{c}\text { Frequency }(F) \geq \text { Frequency Average and } M R O \\
\geq M R O \text { Average }\end{array}$ \\
\hline Third quadrant & Fourth quadrant \\
\hline Contrast Zone & Second Periphery \\
\hline $\begin{array}{c}\text { Frequency }(F)<\text { Frequency Average and } \\
M R O<M R O \text { Average }\end{array}$ & $\begin{array}{c}\text { Frequency }(F)<\text { Frequency Average and } M R O \\
\text { MRO Average }\end{array}$ \\
\hline
\end{tabular}

Source: [9].

\section{Results and Discussions}

After tabulation of the data, we have 419 different words, out of a total of 5224 evocations, these the data were introduced in the software IRAMUTEQ [7], and was carried out a prototypical analysis with the objective of detecting the possible social representations of the researched students in relation to the object Astronomy. 
For this work we considered evocations with frequency greater than or equal to twenty Thus, an average frequency of 89.4 and an average MRO of 4.4 was calculated (Table 3). These parameters where then used for the construction of the four houses, containing the elements belonging to the possible central core and the peripheral region, highlighted in the Table 3 below.

Table 3: Four-house chart showing the social representations of Astronomy elaborated by the students surveyed.

\begin{tabular}{|c|c|c|c|c|c|}
\hline Centr & & & & hery & \\
\hline Frequen & 4 e N & & Frequency & e MI & 4,4 \\
\hline Words & $\mathrm{F}$ & MRO & Words & $\mathrm{F}$ & MRO \\
\hline Planets & 446 & 4,1 & Stars & 312 & 4,4 \\
\hline Astros & 217 & 3,1 & Moon & 173 & 5,1 \\
\hline Galaxies & 200 & 4,1 & Sun & 173 & 4,4 \\
\hline Universe & 184 & 2,9 & Satellites & 156 & 5,4 \\
\hline Spaçe & 166 & 4,2 & Gravity & 140 & 4,5 \\
\hline Study & 157 & 3,2 & Constellations & 130 & 4,8 \\
\hline Physical & 101 & 3,3 & Meteors & 117 & 5,6 \\
\hline Earth & 95 & 4,2 & Astronauts & 110 & 4,6 \\
\hline & & & Astro-telescopes & 95 & 5,5 \\
\hline & & & Movement & 94 & 5,1 \\
\hline & Zone & & Secc & ipher & \\
\hline Frequen & $4 \mathrm{e} \mathrm{M}$ & & Frequency & MR & \\
\hline Words & $\mathrm{F}$ & $\mathrm{MRO}$ & Words & $\mathrm{F}$ & MRO \\
\hline Solar System & 81 & 3,5 & Comets & 88 & 5,7 \\
\hline Astronomers & 69 & 3,7 & Rockets & 65 & 5,1 \\
\hline Life & 57 & 4,1 & Milky Way & 59 & 4,8 \\
\hline Research & 52 & 3,5 & Time & 57 & 5,0 \\
\hline Technology & 50 & 3,7 & Black Hole & 56 & 5,7 \\
\hline Science & 50 & 3,4 & Sky & 54 & 5,1 \\
\hline Big Bang & 37 & 4,0 & Observations & 53 & 4,7 \\
\hline Scientists & 21 & 3,9 & Calculus & 48 & 4,5 \\
\hline Celestial bodies & 20 & 3,5 & NASA & 45 & 4,7 \\
\hline & & & Discoveries & 41 & 5,0 \\
\hline & & & Climate & 40 & 5,6 \\
\hline & & & Phenomena & 39 & 4,9 \\
\hline & & & Light & 38 & 4,8 \\
\hline & & & Eclipses & 38 & 6,0 \\
\hline & & & Atmosphere & 36 & 4,9 \\
\hline & & & Material & 32 & 4,9 \\
\hline & & & Asteroids & 31 & 5,6 \\
\hline & & & Speed & 28 & 5,0 \\
\hline & & & Gases & 27 & 5,5 \\
\hline & & & Spacecraft & 26 & 6,1 \\
\hline & & & Light years & 26 & 5,5 \\
\hline & & & Vacuum & 21 & 5,3 \\
\hline & & & Cosmos & 20 & 4,9 \\
\hline
\end{tabular}

In order to complement the research, students also answered one question related to witch means of information they could use to have access to astronomical topics. Therefore, the following Figure 1, presents the percentage distribution of the possibly consulted 
information sources by the students for acquiring knowledge about Astronomy. In this case, it may be noted that the students surveyed most commonly use the mass media, including internet, cinema and television. On the other hand, it is also verified that books and the school are important sources of information of Astronomy as well.

Figure 1: Percentage of each source of information consulted by students.

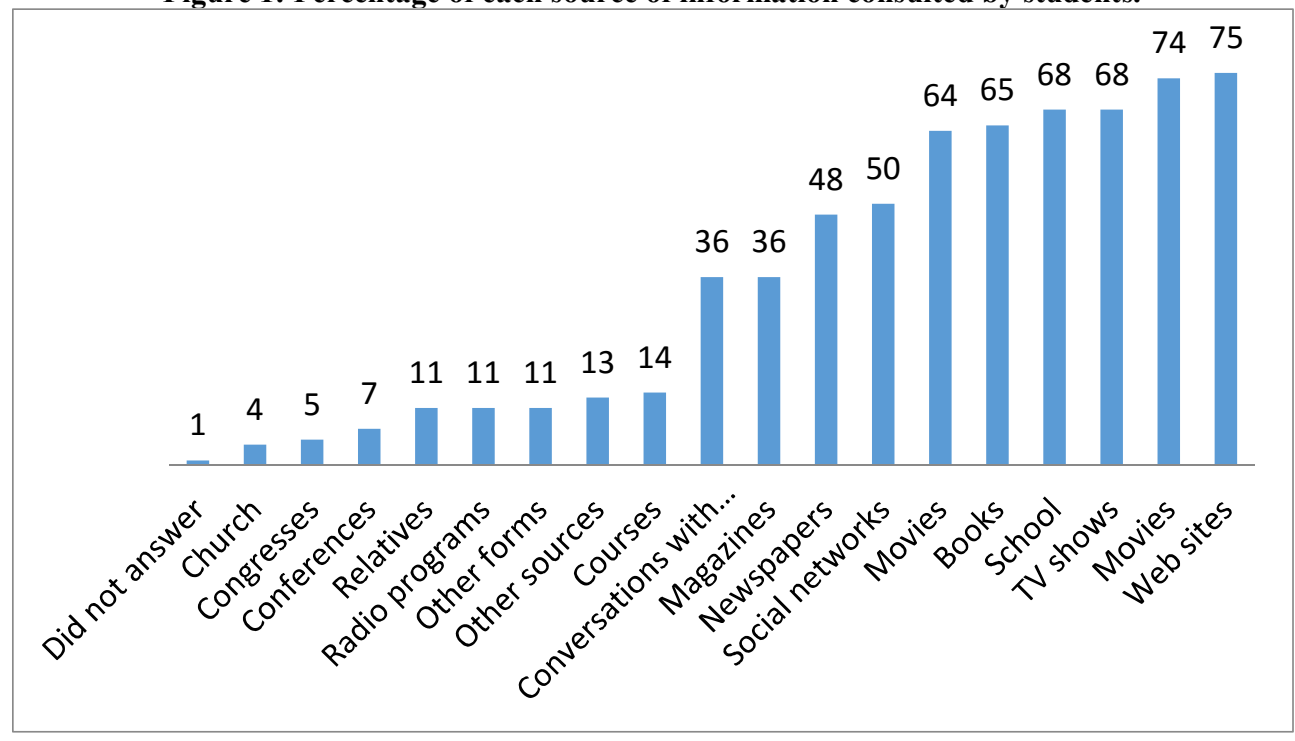

\section{Final Considerations}

In this sense, it is concluded that the students studied have social representations of the object Astronomy, and that these representations are supported both in the elements that compose the field of study of this science, and in those elements that denote the importance of this science in the scope of the formal space and in the development of research and technology for the preservation of life on Earth.

Moreover, it has also been perceived that such representations are based on elements that have made or are part of the experience lived by the respondents within the formal space of education and, on the other hand, are based on possibly divulged elements through the means of mass communication.

The results show that two dimensional elements of social representations are detected in this study: (1) The dimension of information, in this case, it is verified that the social group researched has information and knowledge about the object Astronomy, thus signaling that there is a motivation to know this science; (2) The attitude to this dimension shows that the research group has a favorable position regarding the object, which indicates the importance of teaching this science in Basic Education.

\section{References}

1. LANGHI, R.; NARDI, R. Education in Astronomy: Rethinking Teacher Education. Scriptures, São Paulo, 215 p, 2013.

2. BRAGA, C. F.; TUZZO, S. A. Social representations, communicative acts and media. Intercom Brazilian Society of Interdisciplinary Studies of Communication. XII Conference of Communication Sciences in the Center-West Region - Goiânia - GO, p. 1-15, 27 - 29 May 2010. 
3. JODELET, D. Social representations: An expanding domain. In: JODELET, D. (Org.), ULUP, L. (Translator). The social representations. Rio de Janeiro: Ed. Eduerj, p. 17-44, 2001.

4. MOSCOVICI, S. Social Representations: Investigations in social psychology. 7.ed. Petrópolis, RG: Publishing company, Voices. 404 p, 2010.

5. ABRIC, J. C. The structural approach of social representations. In: MOREIRA, A. S. P.; OLIVEIRA, D.C. (Orgs.). Interdisciplinary studies of social representation. Goiânia: Ed. AB, p. 27-37, 1998.

6. CAMPOS, P. H. F. The structural approach and the study of the relations between practices and social representations. In: CAMPOS, P. H. F. and LOUREIRO, M. C. DA S. (Orgs.) Social representations and educational practices. Goiânia: Ed. UCG, p. 21-36, 2003.

7. RATINAUD, P. IRAMUTEQ: Interface de R pour les Analyses Multidimensionnelles de Textes et de Questionnaires [Computer software]. 2009. Available in: http://migre.me/vrutn.

8. WACHELKE, J.; WOLTER, R. Criteria for Construction and Reporting of Prototypic Analysis for Social Representations. Psychology: Theory and Research, v. 27, n.4, p. 521-526. OctoberDecember 2011.

9. PEREIRA, C. S. A study of the social representations about chemistry of high school students of the Education of Youth and Adults in São Paulo, 2012, 100 p, Dissertation (Master degree) Institute of Chemistry, University of São Paulo, São Paulo. 